\title{
Income Disparities: The Case of Unskilled Workers in Canada (1996-2010)
}

\author{
Samir Amine ${ }^{*}$, Phillippe Scrimger ${ }^{2}$ \\ ${ }^{1}$ Université du Québec en Outaouais, Centre de recherche en politiques publiques (CIRANO), Gatineau, Canada \\ ${ }^{2}$ Ecole de relations industrielles, Université de Montréal, Montréal, Canada \\ Email: samir.amine@uqo.ca
}

Received 15 January 2015; accepted 31 January 2015; published 3 February 2015

Copyright (C) 2015 by authors and Scientific Research Publishing Inc.

This work is licensed under the Creative Commons Attribution International License (CC BY). http://creativecommons.org/licenses/by/4.0/

(c) (j) Open Access

\begin{abstract}
In this paper we analyse the gaps in economic welfare that exist between skilled and unskilled labor in Canada. Following the work of Chardon [1] [2] and Amossé and Chardon [3], we use competency levels as defined in the National Classification of Occupations to distinguish these two groups and then analyse the income disparities that exist between them. Our main findings show that unskilled workers are worse off economically than their skilled counterparts and that the Canadian workforce seems to be more bipolarized than the Canadian population as a whole. We also find strong intra-categorical inequalities within unskilled labor, workers from the sales and services occupational domain being at a disadvantage relative to their peers in other occupational groups. Finally, we show that state intervention, through taxation and social transfers, plays an important role in tightening the inter-categorical and intra-categorical income gaps.
\end{abstract}

\section{Keywords}

Income Gaps, Intra-Categorical, Public Redistribution

\section{Introduction}

If there has always been an ethical case for the reduction income of inequalities, the economic case for such action has not been convincing [4] [5]. Having said this, a recent study from the International Monetary Fund [6] and a forthcoming research initiative by the Organization for Economic Co-operation and Development [7] are unprecedented empirical proof of the negative impact of income inequality on sustainable economic growth. While the economic case for the reduction of income inequality is crystalizing, inequalities themselves are still growing or remain stubborn in most OECD countries [8]. Economic literature suggests a number of root causes

"Corresponding author. 
for these trends, including kill-bias technological change, globalization and off shoring, changes in the supply of skills or an interaction among these forces [9]-[12]. A common element of these drivers of inequality is that they often negatively affect the same vulnerable group - the unskilled. For this reason we argue that one of the key lines of division across which income inequality expresses itself is the income gap between skilled and unskilled workers.

The core interest of this paper is to analyze the recent evolution of the economic situation of unskilled workers in Canada. To our knowledge, very few studies have compared the economic welfare of skilled labor with that of unskilled labor in Canada. The limited studies have completely relied on a definition of unskilled labor that is solely based on the formal educational attainment of individuals (see Massé, Roy and Gingras, 1998). We examined this issue with an approach more in line with previous work by Chardon [1] [2] and Amossé and Chardon [3] in France. With this approach, unskilled workers are defined in terms of competency levels, as established by the Department of Human Resources and Skills Development Canada's (HRSDC) National Classification of Occupations (NCO).

The rest of this paper is divided as follows. Firstly, we focus on methodology and present in greater detail our empirical definition of unskilled labor. In this section, we also provide additional information on the source and type of data used in this study, and the statistical tools used to assess income disparities between the skilled and unskilled. Secondly, we draw a statistical portrait of the evolution of the income gap between skilled and unskilled labor in Canada. Finally, we conclude with our main findings.

\section{Methodology}

\subsection{Definition of Unskilled Labor}

Our empirical distinction between skilled and unskilled work resembles that of Amossé and Chardon [3] who conceptualize it as being the level of adequacy between job content and required training needed to access the occupation. In other words, "an occupation is defined as skilled if its access in early career requires one to have specific training".

In order to differentiate skilled work from unskilled work we use the 2011 National Classification of Occupation (NCO). More specifically, using competency levels as they are described in the NCO, we define skilled workers as those who are in occupations that require higher competencies (levels A or B in the NCO) and unskilled workers as those who are in occupations that generally demand lower competencies(levels $\mathrm{C}$ or $\mathrm{D}$ in the $\mathrm{NCO}$ ).

The NCO bases its ranking of competency levels on an assessment of the typical level of training or education that different occupations necessitate. According to our definition, the threshold between unskilled and skilled labour is located between competency levels B and C. Concretely, this means that occupations that require higher or more specific training than a high school diploma are associated to jobs held by skilled workers. Inversely, unskilled workers are defined as individuals who are in occupations that necessitate a high school diploma or under. In essence, the main difference between skilled and unskilled labour is the level of training or education initially required (at the time of hiring) for the jobs that workers effectively hold.

The data used in this analysis comes from two sources. Information relative to demographics was sourced from Statistics Canada's online CANSIM database that compiles data from the Labour Force Survey (LFS). Information that was unavailable through the CANSIM database was completed with the LFS microdata files. Income data was collected using the microdata files from Statistics Canada's Survey of Labour and Income Dynamics (SLID).

Although these surveys offer important longitudinal data on working conditions and income, they offer limited information on the specific occupation of individuals. In fact, in order to maintain coherence between the two surveys, we were obliged to use an occupational variable in which respondents are classified in one of 25 occupational categories as defined by the National Occupation Classification for Statistics (NOC-S). This sort of aggregation obviously has its drawbacks. To begin, we lose valuable and in-depth information relative to the evolution of unskilled work in some sub-categories. In addition, some of the 25 categories are problematic in the sense that they encompass more than one occupational group, some of them being skilled and others being unskilled according to our definition based on competency levels. For example, one category covers the following professions: chefs and cooks, supervisors and other personnel in the food and drink industry. This means that individuals with competency levels B, C or D are bunched up in the same category which is problematic when trying to compare the evolution of skilled work to unskilled work. 
To resolve issues regarding occupational categories that could not be clearly classified as skilled or unskilled using the NCO, we used a similar approach to that of Chardon [2]. We initially examined how educational attainment was distributed amongst individuals in each problematic occupational branch using the following scale: $0=0-8$ years of education; $1=$ partial high school studies; $2=11-13$ years of education or high school diploma; $3=$ partial postsecondary studies; $4=$ postsecondary diploma or certificate; $5=$ Bachelors degree; $6=$ graduate degree. Knowing that the highest educational attainment typically associated with competency levels $\mathrm{C}$ and D of the NCO (our definition of unskilled workers) is a high school diploma or short job specific training, we used level 3 as a cut-off. In other words, we define unskilled individuals as those who have a level of educational attainment that is equal to or lesser than 3, and skilled workers as those who are located above level 3.

For those groups with a mix of skilled and unskilled workers, we then verify if one skill group dominated the other in each problematic occupational branch, that is to say, if one skill group holds a proportion of individuals that is significantly higher than $50 \%$. In the end, five out of the 25 occupational categories were found to be problematic. Within these five problematic categories, four of them had a dominating skill group that held approximately $65 \%$ of group population. The fifth occupational category was not as strongly dominated byone skill group, but level 3 and under individuals still held a significant majority $(60 \%)$ of the total occupational population.

\subsection{Bipolarisation Measure}

Having shown how we have delineated skilled and unskilled work, we now turn the definition of the analytical tools used to grasp the economic inequalities between the two groups. The better part of our analysis relies on standard descriptive statistics, leaning mostly on the evolution of median incomes. A more sophisticated bipolarisation index is also applied in order to measure the extent to which the labor market is polarized into two income groups. This measure is the Pfw bipolarisation index first developed by Foster and Wolfson [13] [14] and is expressed as follows:

$$
P f w=2(2 T-G) /(\mu / m)
$$

where $\mu$ and $m$ are respectively the mean and median income, $T=\left(\mu^{U}-\mu^{L}\right) / \mu$, where $\mu^{U}$ is the mean income of individuals situated above the median and $\mu^{L}$ is the mean income of those located below the median, and $G$ is the Gini coefficient value of the whole distribution. In more practical terms, $P f w$ takes a value between $[0,1]$, where zero represents a situation where all individuals in the distribution have the same income and 1 describes a situation of perfect polarization where one half of the population have an income equal to zero and the other half, the more economically affluent half, have an income equal to twice the average.

Polarization measures are becoming more and more popular than traditional inequality measures in income inequality research as they are said to be a more valid assessment of group dynamic and social unrest [15], and providea better indicator of what the public truly perceives as economic inequality [16]. In Canada alone, several studies have shifted towards polarization measures to assess recent distributional trends and in many cases Pfw was the main analytical tool [13] [14] [17]-[24].

Before we turn to the results, a few additional comments are necessary regarding the types of income data used in this study. In essence, we analyze two types of income: "market income" (MI); "after taxes and transfers income" (ATTI). On the one side, market incomes represent the income level that an individual attains by interacting freely with the market before government intervention. The way "market incomes" are allocated in a society is said to represent the "natural" distribution of income because it is the result of market forces alone. On the other side, "after taxes and transfers income" is said to measure the "real" distribution and is defined as follows: (market income + government transfers - taxes). The advantage of using both these types of income is that together they offer an indication of the extent of government intervention in the reduction of income inequality and polarization. This way of analyzing government intervention has become common practice and is used in recent inequality studies [6] [25]. As for our research, the difference between MI and ATTI will allow us to grasp the extent to which government policy has historically impacted the gap in economic welfare between skilled and unskilled workers.

\section{Results}

We present our statistical portrait of the evolution of unskilled workers in Canada in three steps. First, we esti- 
mate the weight of unskilled labor in the total Canadian workforce. Next, we compare the inter-categorical income disparities between skilled and unskilled workers in order to assess the strength of this line of division in the labor market. Lastly, we evaluate intra-categorical disparities by comparing the economic welfare between unskilled labor occupational groups.

\subsection{Evolution of Unskilled Labor}

According to our estimates, there were just over 7.7 million unskilled workers in Canada in 2012. In relative terms, this represented a little less than half (44.11\%) of the Canadian Workforce. As shown in Figure 1, since the early 2000s, unskilled labor has seen its relative weight diminished. In fact, from 2000 to 2012, the numbers show a reduction equal to 3.4 percentage points, that is to say an absolute drop of seven percent.

Nonetheless, what these figures show is a near 50/50 split between skilled and unskilled workers on the Canadian labor market. This demonstrates that unskilled workers are not a small and isolated group, but rather a significant portion of the Canadian workforce. This group is particularly vulnerable to environmental forces (technological change, globalization, and economic downturns) and to more precarious working conditions (part-time work, temporary employment, seasonal work, etc.). Now that we have assessed the size of the interest groups, we now turn to the income disparities that exist between them.

\subsection{Skilled-Unskilled Income Gap}

To determine inter-categorical inequalities, we examine the income gap that exists between both main groups (skilled and unskilled). As Figure 2 illustrates, both groups have experience a sustained and proportionally similar

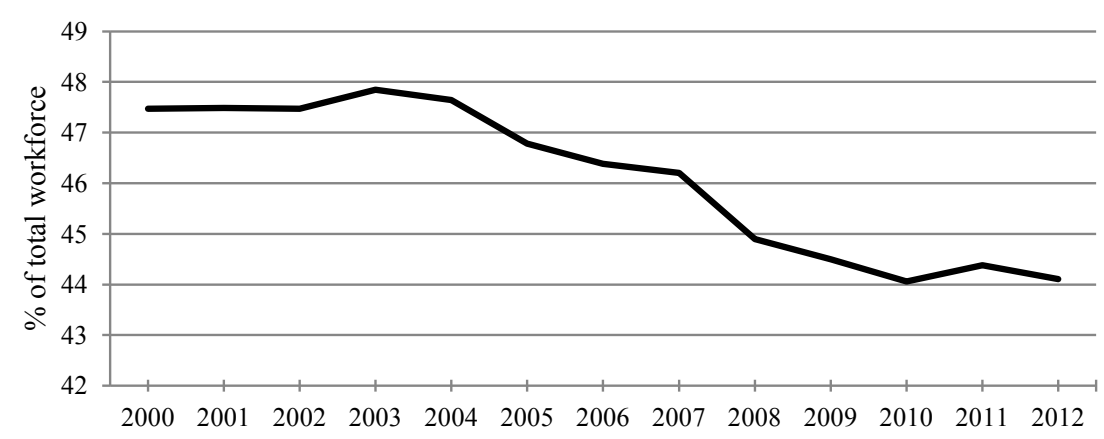

Figure 1. Evolution of the share of unskilled labor in total workforce (2000-2012). Data source: CANSIM table 282-0010 and LFS.

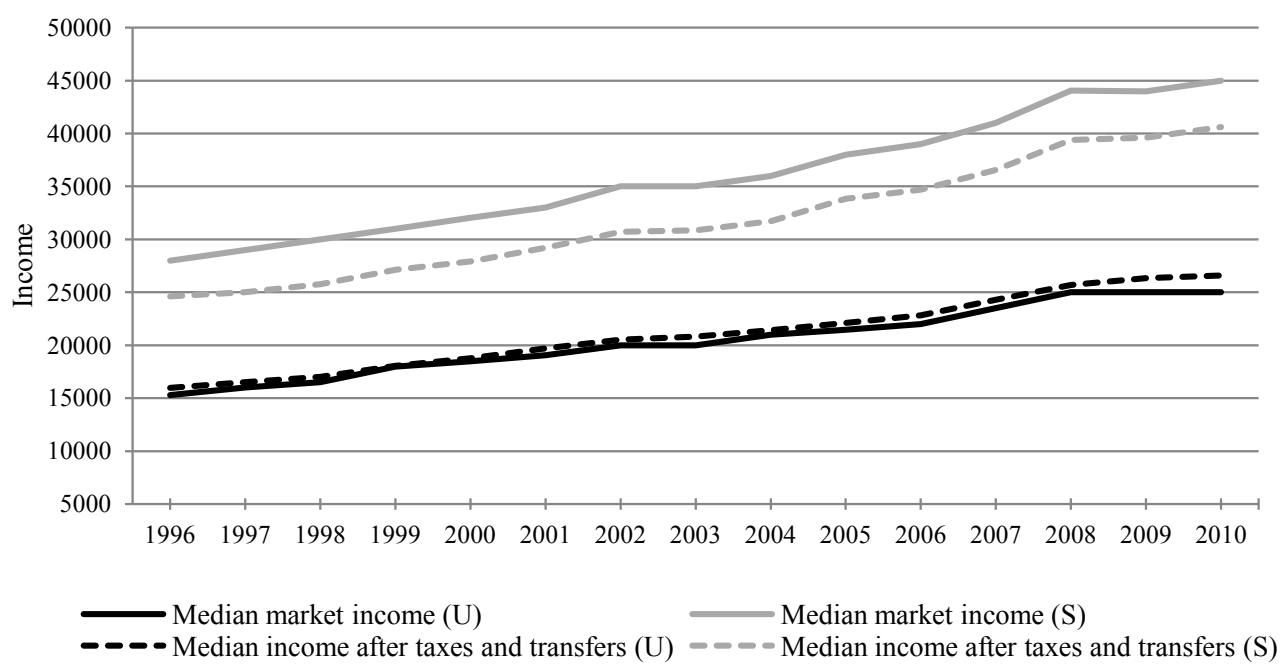

Figure 2. Evolution of the median income among skilled and unskilled workers in Canada (19962010). Data source: SLID. 
increase in their nominal incomes since the mid-1990s. Indeed, since 1996, the median market income (MI) and median after taxes and transfers income (ATTI) of unskilled workers has risen by $38.90 \%$ and $39.87 \%$ respectively. The same figures for skilled labor are $37.78 \%$ and $38.38 \%$. Income growth seems then fairly balanced between the two groups.

Having said this, as it is apparent in Figure 2, there does exist a clear income gap between the two skill groups. If we look at market incomes, at the beginning of the period of interest, the median unskilled worker had an MI equal to $54.55 \%$ of his skilled counterpart. This ratio was slightly increased at the end of the period to a level of 55.56\%. Turning our focus to after taxes and transfers incomes, we notice a considerable reduction in inequality. In 1996, the median unskilled worker had an ATTI equal to $64.89 \%$ of his skilled equivalent. In 2010 , the same ratio marginally increased to $65.42 \%$. Government intervention through taxation policy and social transfers has served as an important equalizing measure. Furthermore, it would seem that government led redistribution has maintained its effectiveness since the mid-1990s as the income gaps between the skilled and the unskilled has been virtually stable. Evidently, the relative stability of these wage gaps is mostly due to skilled and unskilled labor's similar income growth patterns.

To determine if the labor market is truly divided along the lines of two income groups, we now turn to our bipolarization measure. As mentioned above, the $P f w$ varies from 0 to 1 , where 0 indicates income equality and 1 refers to a situation of perfect bipolarization. As it can be seen in Figure 3, income bipolarization seems to be lightly diminishing in Canada since the mid-1990s. From 1996 to 2010, market income bipolarization steadily dropped from 0.4622 to 0.4205 or roughly $9.02 \%$. After taxes and transfers income bipolarization follows a similar trend dropping from 0.3460 to 0.3226 or $6.76 \%$.

The trends in Figure 3 also show that state intervention has maintained its effectiveness in reducing bipolarization on the Canadian labor market. Specifically, at the beginning of the observed period, taxation policy and social transfers reduced market bipolarization by approximately $25.14 \%$, which reduced slightly by the end of the period to $23.28 \%$. Overall, government intervention has reduced, on average, income dualization by $23.34 \%$ since the mid-1990s.

As for the relative intensity of the bipolarization shown by our results, we find that our estimates indicate a slightly higher bipolarization level than Goyette's [21] study. This situation is necessarily due to methodological differences. Where Goyette focused on the entire Canadian population, we concentrate solely on the Canadian workforce. In addition, where Goyette used individual incomes adjusted to family size as a unit of analysis, focusing on workers alone, we use the individual incomes of workers regardless of family size. Ultimately, the differences in results do not indicate that the income distribution of the Canadian population as a whole is in fact more equal than the allocation of incomes within the subpopulation of the Canadian workforce. This may indicate is that Canadian workers are even more clearly divided in two well-defined income groups than the general

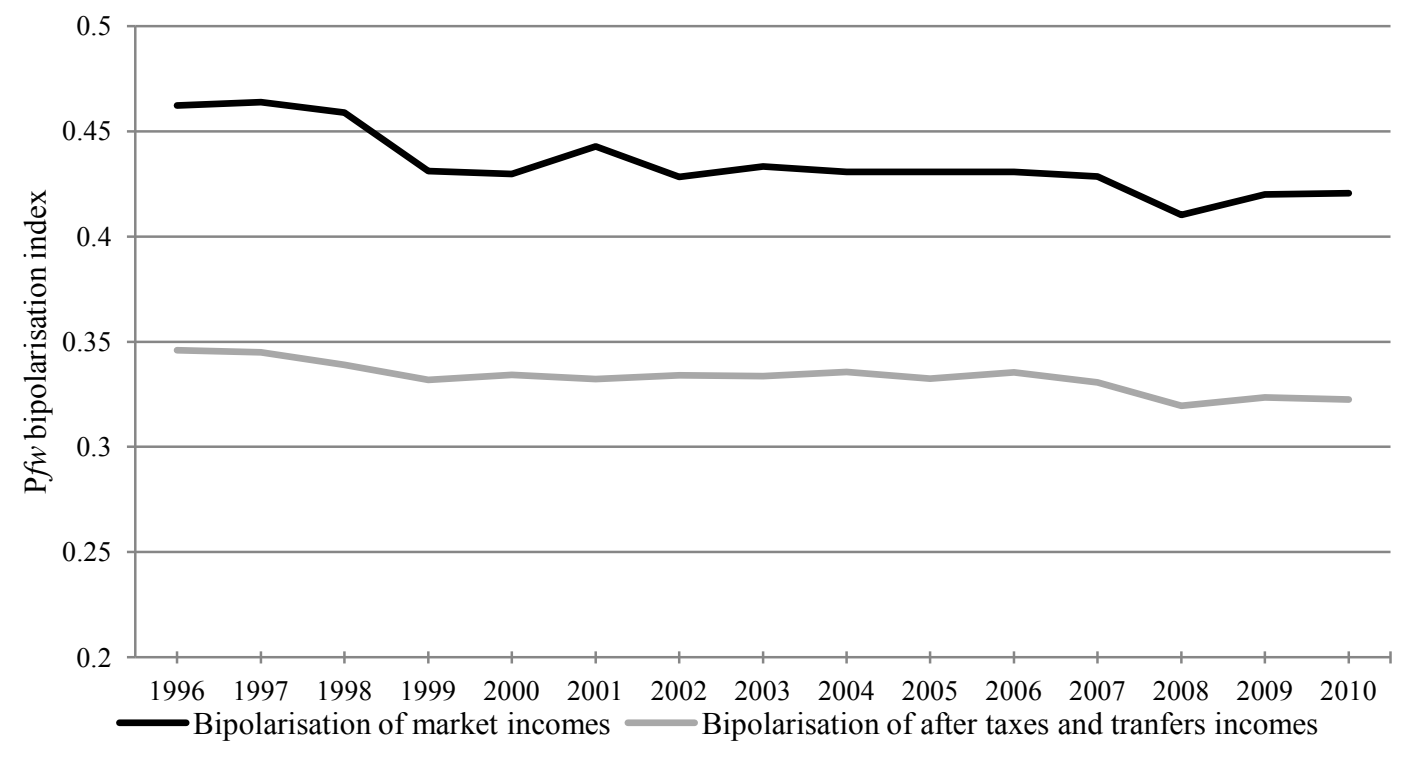

Figure 3. Evolution of the polarization of income among Canadian workers (1996-2010). Data source: SLID. 
population. Furthermore, the skilled-unskilled division may be an important determinant of income disparities in the Canadian society as a whole.

\subsection{Inequalities among Unskilled}

The previous two subsections of this paper have focused on the skilled-unskilled distinction. We now turn our focus to intra-categorical inequalities and analyze the income disparities that exist within the unskilled labor group.

Figure 4 shows the evolution of median market incomes across main occupational groups of unskilled labor. Quickly, we notice two main income groupings. The first one (Group 1) is composed of three occupational groups (business, finance and administration, trades, transport and equipment and operators, and processing, manufacturing and public utility services) and is clearly the more affluent of the two. The second cluster (Group 2), is formed by workers from occupational families relative to sales and services, on the one hand, and occupations unique to the primary sector, on the other hand. Having said this, towards the end of the period, Group 2 is becoming more and more divided as the income of workers from the primary sector begins to grow much faster than their counterparts from sales and services. It is our understanding that this trend could be explained, at least in part, by the boom in the oil industry in western Canada and Newfoundland.

More specifically, the largest market income gaps between occupational groups are observed towards the end of the 2000s. Looking at extreme cases, we notice at the end of the studied period that the median worker in sales and services received an income equal to $47.65 \%$ of his homologue in the processing, manufacturing and public utility services occupational group. This ratio has grown approximately 3.49 percentage points since 1996, when it was equal to $44.17 \%$.

Figure 5 shows the evolution of median incomes for the same occupational groups, but this time, after taxation and social transfers have come into effect. As expected in light of previous results, after taxes and transfers median incomes show much tighter gaps. If we look at extreme differences again, we see that the median worker in the less fortunate group received about $55.59 \%$ of the same worker in the most well off group in 1996. In 2010, the same ratio was equal to $59.38 \%$. Also, it becomes evident that while the Group 1cluster seems to hold, group 2 is clearly broken up. Workers in occupations unique to the primary sector are now clearly much better off than their counterparts in sales and services.

The findings in Figure 4 and Figure 5 become more problematic when we consider that workers are overrepresented in the least well off occupational group (sales and services). In fact, in 2010 approximately $28.28 \%$ of

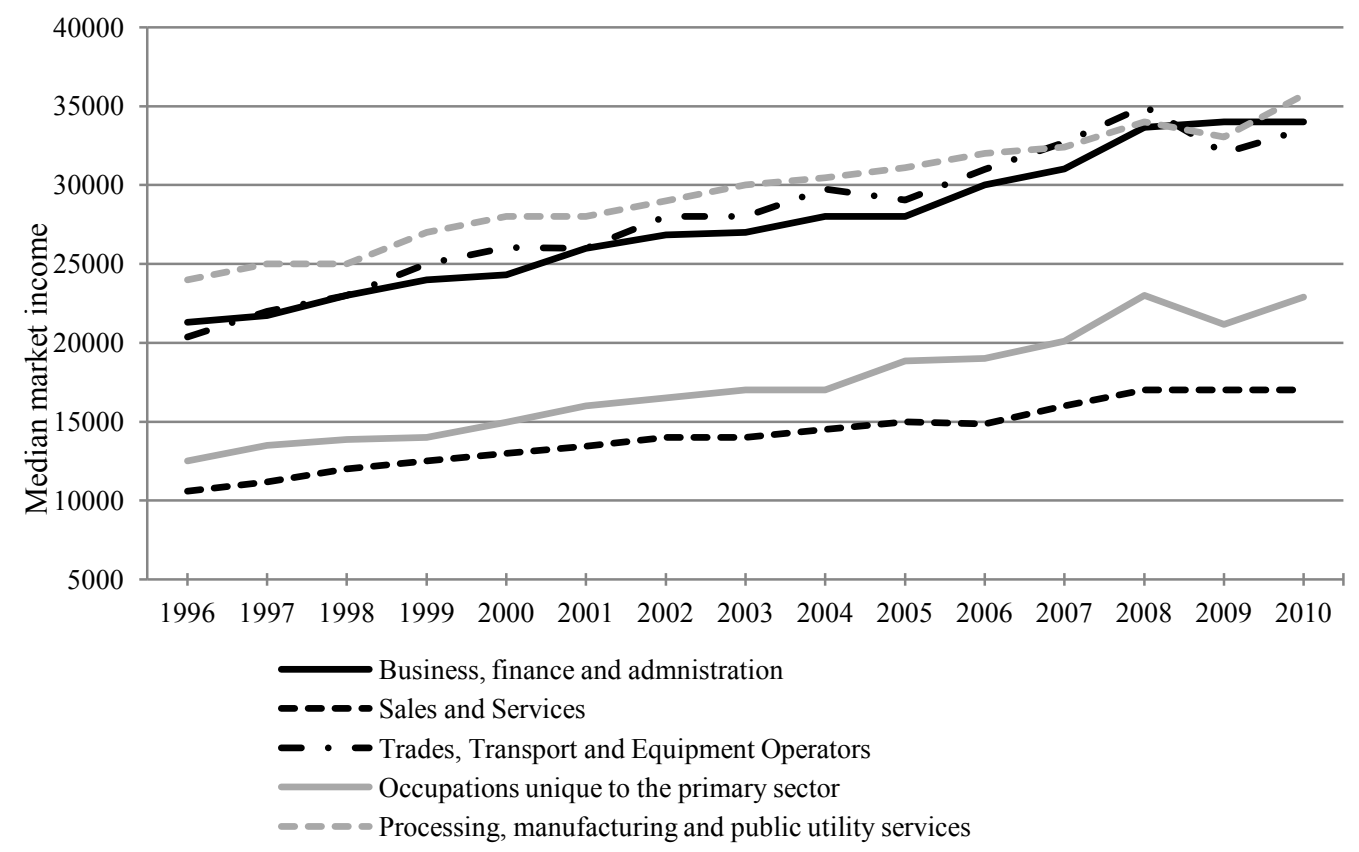

Figure 4. Evolution of market income among unskilled workers by occupational group (1996-2010). Data source: SLID. 


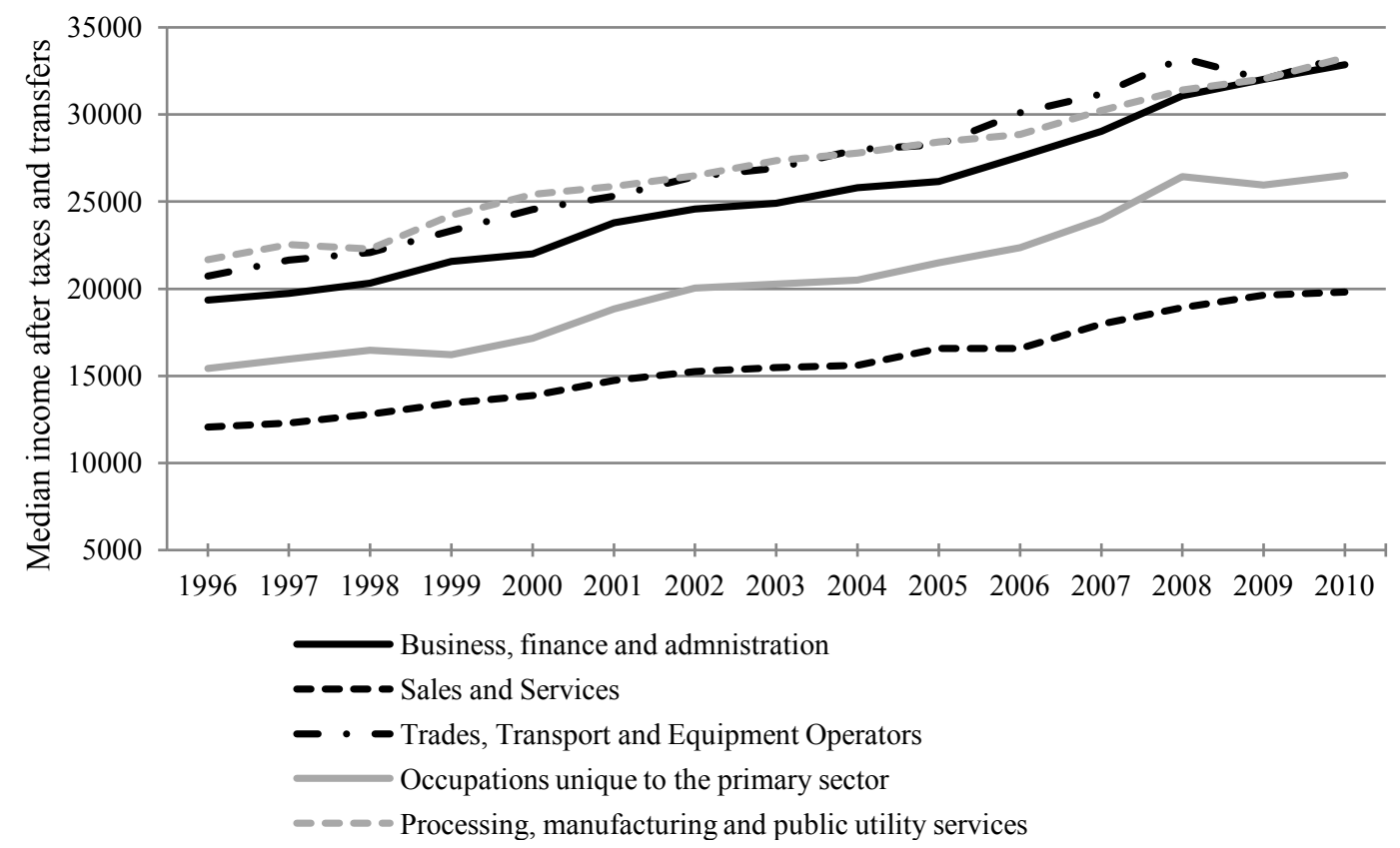

Figure 5. Evolution of after taxes and transfers income among unskilled workers by occupational group (1996-2010). Data source: SLID.

all unskilled workers were part of the sales and services occupational group. In addition, workers occupied in this group are much more likely than their peers from other occupational domains to work part-time jobs and more prone to having precarious employment contracts.

In sum, we observe that unskilled workers are themselves a fragmented group, with some occupational subgroups enjoying significantly higher medians incomes. Intra-categorical inequalities among the unskilled then seem to explain an appreciable amount of inequalities between members of the Canadian workforce.

\section{Final Remarks}

In this paper we have analysed the gaps in economic welfare that exist between skilled and unskilled labor in Canada. Using a method similar to Chardon [1] [2] and Amossé and Chardon [3] to distinguish these two groups, we analysed the income disparities that exist between them. Our main findings are as follows:

1) The proportion of unskilled workers is slowly reducing, but still represents almost half of the workforce in Canada in 2012;

2) Income gaps between the skilled and unskilled remain constant and appreciable;

3) Income bipolarization has lightly decreased since the mid-1990s, but, comparing our estimates with other studies, we find that the Canadian workforce seems to be more bipolarized than the Canadian population as a whole;

4) Intra-categorical inequalities within unskilled labor seem to be increasingly important among occupational subgroups, mainly workers in sales and services being at a great disadvantage compared with their peers in other unskilled occupational domains;

5) In every case, state intervention considerably diminishes inter-categorical and intra-categorical income gaps and has maintained its effectiveness over the observed period.

\section{References}

[1] Chardon, O. (2001) Les transformations de l'emploi non qualifié depuis vingt ans. Insee Première, No. 796, Insee, 4 p.

[2] Chardon, O. (2002) La qualification des employés. Document de Travail, No. F 0202, Insee, 33 p.

[3] Amossé, T. and Chardon, O. (2006) Les travailleurs non qualifies: Une nouvelle classe sociale? Économie et Statistique, No. 393-394, Insee, 203-229.

[4] Feldstein, M. (1998) Income Inequality and Poverty. National Bureau of Economic Research, Working Paper 6770, 12 
p.

[5] Fields, G.S. (2007) How Much Should We Care About Changing Income Inequality in the Course of Economic Growth? ILR Collection, $16 \mathrm{p}$.

[6] Ostry, J.D., Berg, A. and Tsangarides, C.G. (2014) Redistribution, Inequality and Growth. IMF Staff Discussion Note, $30 \mathrm{p}$.

[7] Scarpetta, S. (2014) Nouvelles approches en matière de réduction des inégalités et de politiques d'emploi. Forum Pour un Québec prospère 2014 of the Association des économistes québécois (ASDEQ), Québec, 3 June 2014, 25 p.

[8] OCDE (2011) Growing Income Inequality in OECD Countries: What Drives It and How Can Policy Tackle It? Éditions OCDE, Paris, $17 \mathrm{p}$.

[9] Atkinson, A.B. (2007) The Distribution of Earnings in OECD Countries. International Labour Review, 146, 41-60. http://dx.doi.org/10.1111/j.1564-913X.2007.00004.x

[10] Amine, S. (2011) Les institutions du marché du travail et les inégalités inter-catégorielles: Une Comparaison FranceCanada. Revue Multidisciplinaire sur l'Emploi, le Syndicalisme et le Travail, 6, 5-19. http://dx.doi.org/10.7202/1000447ar

[11] Amine, S. (2012) "Low-Skilled” Work in Canada. Economic and Labour Relations Review, 23, 91-100. http://dx.doi.org/10.1177/103530461202300407

[12] OCDE (2011) Tour d'horizon des inégalités croissantes de revenus dans les pays de l'OCDE: Principaux constats. Éditions OCDE, Paris, $27 \mathrm{p}$.

[13] Foster, J. and Wolfson, M.C. (1992) Polarization and the Decline of the Middle Class: Canada and the US. Oxford Poverty \& Human Development Initiative (OPHI) Working Paper No. 31, Oxford, 30 p.

[14] Foster, J. and Wolfson, M.C. (2010) Polarization and the Decline of the Middle Class: Canada and the US. Journal of Economic Inequality, 8, 247-273. http://dx.doi.org/10.1007/s10888-009-9122-7

[15] Esteban, J.M. and Ray, D. (1994) On the Measurement of Polarization. Econometrica, 62, 819-851. http://dx.doi.org/10.2307/2951734

[16] Amiel, Y. and Cowell, F.A. (1992) Measurement of Income Inequality: Experimental Test by Questionnaire. Journal of Public Economics, 47, 3-26. http://dx.doi.org/10.1016/0047-2727(92)90003-X

[17] Wolfson, M.C. (1994) When Inequalities Diverge. The American Economic Review, 84, 353-358.

[18] Wolfson, M.C. (1997) Divergent Inequalities: Theory and Empirical Results. Review of Income and Wealth, 43, 401421. http://dx.doi.org/10.1111/j.1475-4991.1997.tb00233.x

[19] Wolfson, M.C. and Murphy, B. (1998) Une nouvelle perspective des tendances de l'inégalité des revenus au Canada et aux Etats-Unis. Statistique Canada, 11F0019MPF, No. 124, Ottawa, 29 p.

[20] Jean, S. (2001) Inégalité et pauvreté. In: Institut de la statistique du Québec, Ed., Portrait Sociale du Québec: Données et Analyses Éditions 2001, Direction des statistiques sociodémographiques, Québec, 317-337.

[21] Goyette, M.A. (2007) Évolution de la polarisation au Canada: 1973-2003. Mémoire de Maitrise inédit, Université Laval, Québec City, 144 p.

[22] Heisz, A. (2007) Income Inequality and Redistribution in Canada: 1976 to 2004. Statistique Canada, Analytical Studies Branch Research Paper Series, Ottawa, 58 p.

[23] Araar, A. (2008) Social Classes, Inequality and Redistributive Policies in Canada. Cahiers de recherche 0817, CIRPEE, Québec, $25 \mathrm{p}$.

[24] Scrimger, P. (2014) Évolution de la polarisation des revenus au Québec (2000-2009). Mémoire de Maîtrise inédit, Université du Québec en Outaouais, Gatineau, 87 p.

[25] OCDE (2012) Inégalités de revenus et croissances: Le rôle des impôts et des transferts. Éditions OCDE, Paris, 14 p. 
Scientific Research Publishing (SCIRP) is one of the largest Open Access journal publishers. It is currently publishing more than 200 open access, online, peer-reviewed journals covering a wide range of academic disciplines. SCIRP serves the worldwide academic communities and contributes to the progress and application of science with its publication.

Other selected journals from SCIRP are listed as below. Submit your manuscript to us via either submit@scirp.org or Online Submission Portal.
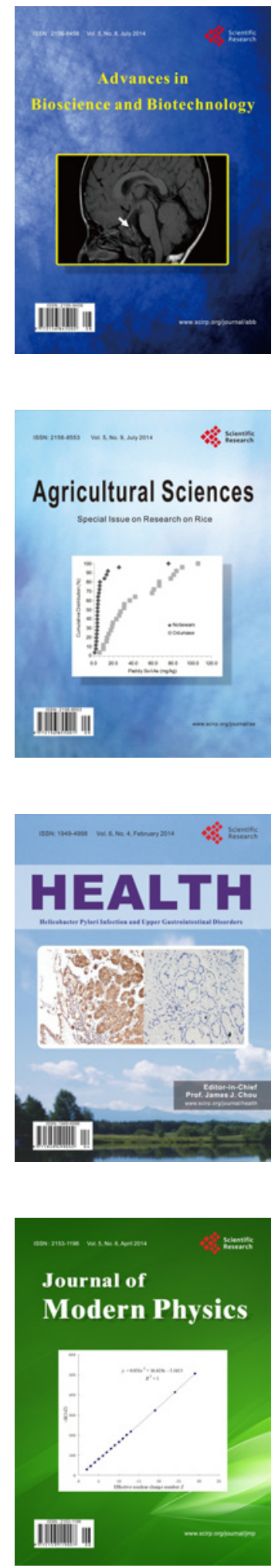
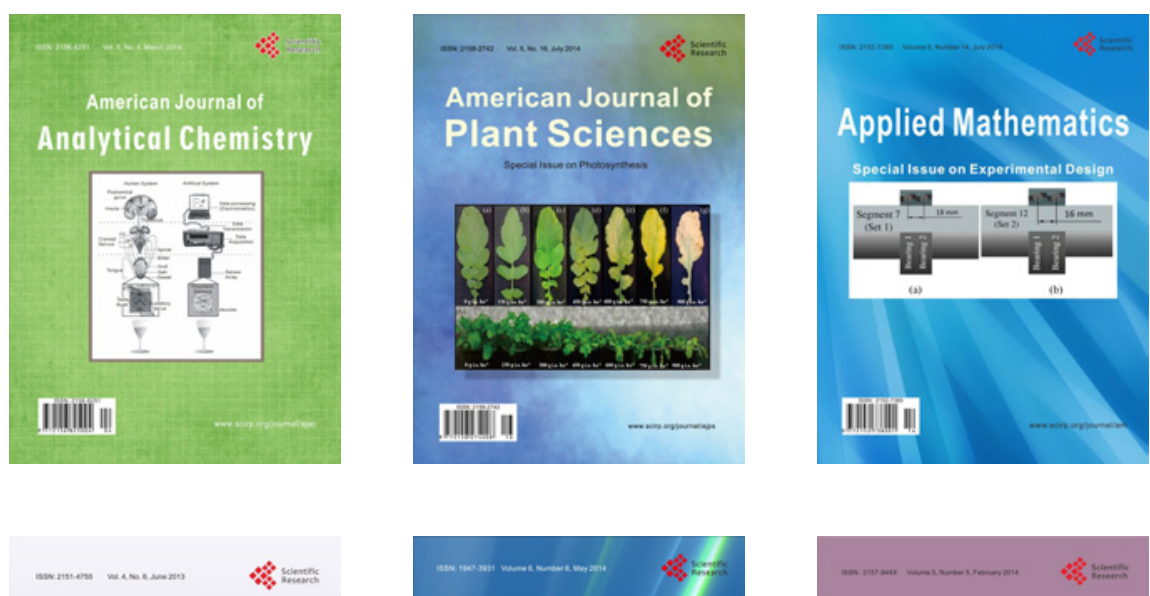

Creative Education
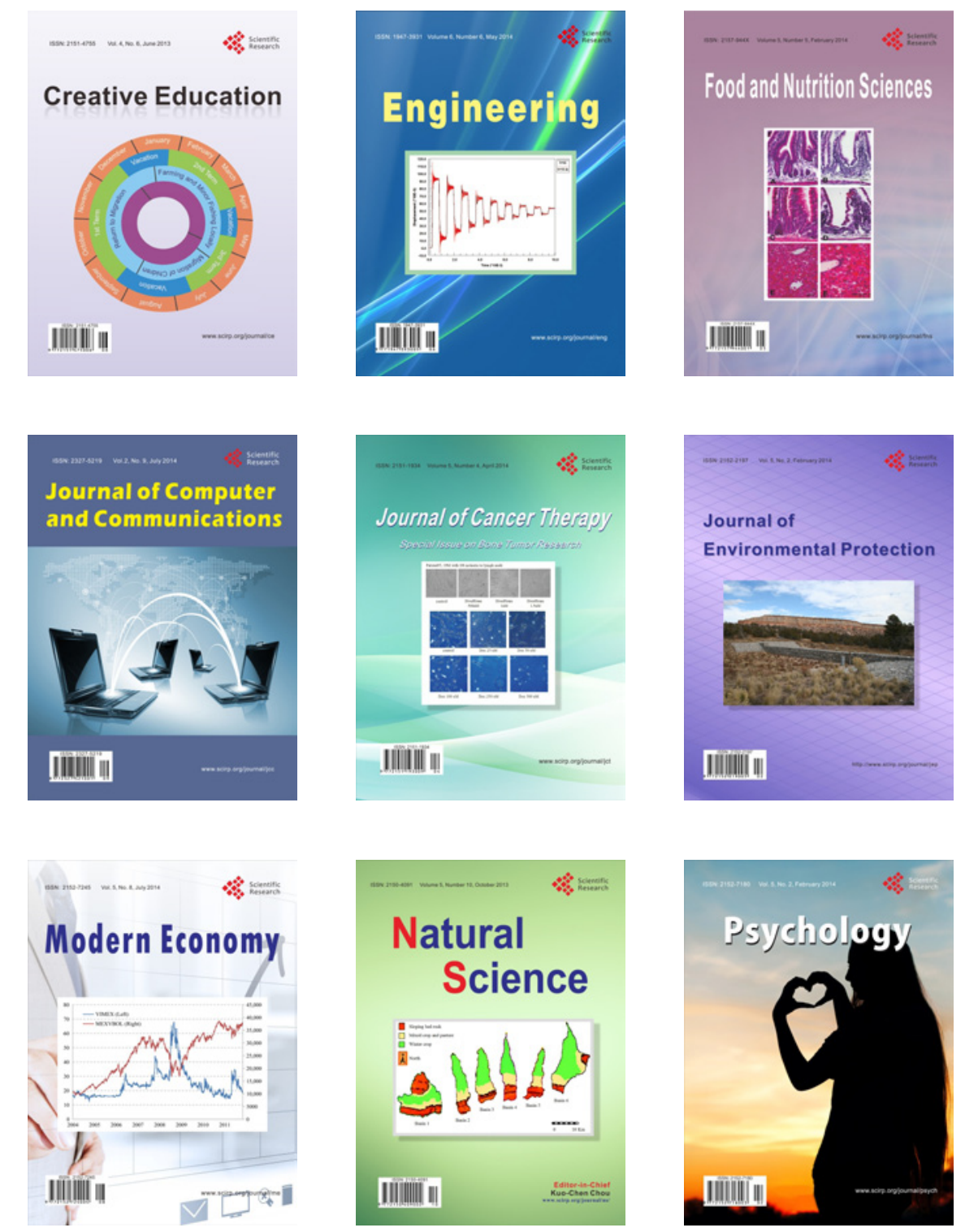